SECTION 24. Sociological research.

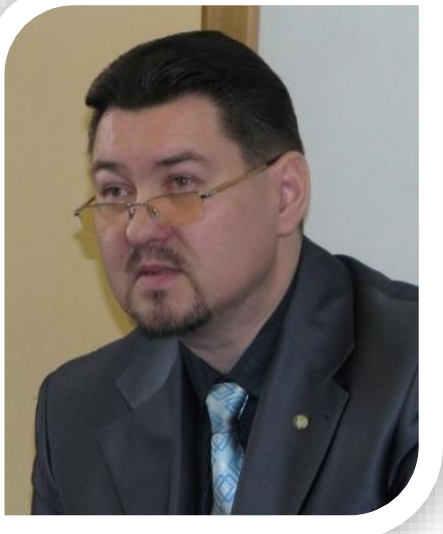

Molodov Oleg Borisovich Candidate of Historical Sciences, Senior Research Associate, Institute of Socio-Economic Development of Territories of Russian Academy of Science, Russia o_young8172@mail.ru

\title{
TRANSFORMATION OF MEDIA SPACE AND RELATION TO MASS MEDIA OF THE POPULATION OF THE VOLOGDA REGION
}

Abstract: Article is devoted to the changes in the Russian media space. Traditional mass media keep the competitiveness, despite growth of popularity of the Internet, as researches shows. The relation of Russians and inhabitants of the Vologda region to the various mass media, based on monitoring of public opinion, is characterized in it.

Key words: state, civil society, mass media, Internet, trust, population, region.

УДК 316.77

\section{ТРАНСФОРМАЦИЯ МЕДИЙНОГО ПРОСТРАНСТВА И ОТНОШЕНИЕ К СМИ НАСЕЛЕНИЯ ВОЛОГОДСКОЙ ОБЛАСТИ}

Аннотация. Статья посвящена изменениям, происходящим в медийном пространстве современной России. Исследования показывают, что несмотря на рост популярности интернета, традиционные СМИ сохраняют свою конкурентоспособность. На материалах мониторинга общественного мнения характеризуется отношение россиян и жителей Вологодской области к различным СМИ.

Ключевые слова: государство, гражданское общество, средства массовой информаџии, интернет, доверие, население, область.

Средства массовой информации Вологодской области, как и России в целом, представляют собой совокупность различных источников, в первую очередь, так называемых традиционных. К ним относятся телевидение, радио, печатные масс-медиа (журналы и газеты). В последние годы происходят существенные изменения в этой сфере, связанные с процессами глобализации и информатизации общественной жизни. Обострилась конкуренция традиционных СМИ и интернета, который будучи более независимым источником информации, приобретает всё большее доверие пользователей.

Предметом дискуссии в социологии и журналистике является роль и значение телевидения как источника информации. Появилось мнение о том, что с развитием интернета «ящик сыграет в ящик» [17], однако другие исследователи прогнозирует адаптацию телевидения к новым реалиям и сохранение за ним массовой аудитории в течение длительного времени [2, с. 98]. По данным социологического исследования аналитического центра «Видео», в 2008 г. до 37\% выросло число домохозяйств, 
оснащенных двумя телеприёмниками, и до $11 \%$ - тремя и более. В среднем каждое домохозяйство принимало 21 телеканал [11, с. 130]. Вместе с тем, в отдалённых населённых пунктах жители по-прежнему имеют возможность смотреть только основные федеральные телеканалы, в результате содержание повестки для части российского общества - это во многом отражение того, что показывает телевидение [8, c. 46].

По данным ВЦИОМ, общая степень доверия россиян к СМИ возросла за четыре года (2008-2011 гг.) с 49 до 53 \% [10]. При этом больше всего россиян доверяли в 2011 г. центральному телевидению (69\%), региональному и местному телевидению (56\%), центральным, региональным и местным газетам и журналам (42\%). Меньшая степень доверия оказана центральному радио и интернету (по $35 \%$ ), региональному и местному радио (30\%) и зарубежным СМИ (16\%). Согласно данным ВЦИОМ, на «традиционные СМИ, то есть отечественное телевидение, радио и печать, ориентированы преимущественно женщины, пенсионеры, селяне и люди с низким доходом и низким уровнем образования» [13].

По итогам последних четырёх лет (2010-2013 гг.) практически все традиционные медиа потеряли позиции в плане доверия к их информации: телевидение - с 79 до 51\%, газеты - с 16 до 12\%, радио - с 23 до 12\%. Напротив, поднялось доверие к интернет-изданиям (с 7 до 14\%) и социальным сетям (с 4 до 11\%), практически догнав газеты и радио. По данным ФОМ за март 2013 г., в России ежедневно пользуется интернетом 50 млн. человек (раз в месяц и чаще - 64 млн. чел.). Однако наиболее популярными целями посещения сетевых ресурсов является поиск информации, причём не всегда актуальной, и общение. По данным Левада-центра, лишь третье место с результатом 27\% разделили развлечения и собственно отслеживание последних новостей. Критически настроенные исследователи отмечают, что власти должны быть обеспокоены процессом роста популярности интернета и социальных сетей в качестве источника информации, поскольку там формируется иная повестка дня и власть не определяет правила игры [12].

Телевидение остаётся самым популярным источником информации для 88\% граждан, а почти половина россиян ему больше всего доверяет. Интернет-издания пока не «в почёте»: только 21\% граждан узнаёт оттуда новости, а доверяют сведениям из сети лишь 14\%. По мнению И. Петровской, члена Академии российского телевидения, это объясняется советскими традициями, когда информации верили только потому, что её показали в программе «Время». Однако с ростом интернет-аудитории у большинства граждан появится возможность сопоставлять информацию из различных источников, и доверие к новостным выпускам центральных телеканалов снизится. Директор фонда «Общественная экспертиза» И. Яковенко отмечает, что развитие интернета не приводит к тому, что он становится основным источником информации, поскольку ищет в сети общественно-политические новости меньшинство пользователей [14].

Общероссийские данные подтверждаются результатами мониторинга общественного мнения жителей Вологодской области о СМИ, проводимого ИСЭРТ РАН (табл. 1).

Телевидение остается основным источником информации о политической и экономической жизни для $84 \%$ населения, а также сведений культурноразвлекательного характера для 79\%.

Продолжает возрастать роль интернета как источника информации: доля жителей области, получающих оттуда информацию о политической и экономической жизни, составила в 2011 г. - 25\%, в 2012 г. - 26\%, в 2013 г. - 35\%. О культурных, спортивных событиях и развлечениях узнавали из сети в 2011 г. $-30 \%$ населения, в 2012 г. - 31\%, в 2013 г. - 37\%. Количество его пользователей увеличилось преимущественно среди женщин (с 30 до 39\%), жителей области в возрасте до 30 лет (с 
62 до 72\%), лиц с высшим и незаконченным высшим образованием (с 52 до 67\%), 20\% наиболее обеспеченных граждан (с 45 до 62\%) и жителей Вологды (с 34 до 47\%).

Таблица 1

Доля жителей, пользующихся средствами массовой информации, (\%) ${ }^{1}$

\begin{tabular}{|l|c|c|c|c|c|c|}
\hline \multicolumn{1}{|c|}{$\begin{array}{c}\text { Варианты } \\
\text { ответов }\end{array}$} & $\mathbf{2 0 0 8}$ & $\mathbf{2 0 0 9}$ & $\mathbf{2 0 1 0}$ & $\mathbf{2 0 1 1}$ & $\mathbf{2 0 1 2}$ & $\mathbf{2 0 1 3}$ \\
\hline Смотрят телевизор & 96,1 & 95,3 & 96,1 & 95,7 & 94,7 & 94,7 \\
\hline Слушают радио & 68,3 & 68,1 & 63,4 & 67,2 & 69,0 & 66,3 \\
\hline Читают газеты & 76,9 & 72,3 & 73,7 & 66,3 & 63,5 & 64,9 \\
\hline $\begin{array}{l}\text { Всего жителей области, } \\
\text { пользующихся СМИ }\end{array}$ & 98,9 & 98,9 & 98,4 & 98,6 & 96,8 & 97,3 \\
\hline
\end{tabular}

Ежедневно пользуются интернетом 41\% населения Вологодской области, причём среди жителей Череповца 51\%, Вологды - 44\% (табл. 2). С учётом использующих сетевые ресурсы по несколько раз в неделю (15\% жителей области) доля активных пользователей составляет по области 56\%, а в Череповце - 67\%.

Как часто Вы пользуетесь Интернетом?, \% *

Таблица 2

\begin{tabular}{|l|c|c|c|c|}
\hline \multicolumn{1}{|c|}{ Варианты ответов } & Вологда & Череповец & районы & область \\
\hline Практически ежедневно & 44,0 & 50,5 & 34,8 & 41,3 \\
\hline Несколько раз в неделю & 13,6 & 16,5 & 14,9 & 15,0 \\
\hline Несколько раз в месяц & 7,3 & 5,6 & 6,1 & 6,3 \\
\hline $\begin{array}{l}\text { Эпизодически, но не менее } \\
\text { одного раза в полгода }\end{array}$ & 4,2 & 1,5 & 1,5 & 2,2 \\
\hline Не пользуюсь интернетом & 26,2 & 22,6 & 33,6 & 28,8 \\
\hline Затрудняюсь ответить & 4,7 & 3,3 & 9,1 & 6,5 \\
\hline $\begin{array}{l}\text { Источник: Данные мониторинга ИСЭРТ РАН } \\
\text { * Опрос проводился в декабре 2013 г. }\end{array}$ \\
\hline
\end{tabular}

При этом интернет пока не в силах полностью заместить традиционные СМИ и прежде всего телевидение. По данным Левада-центра (август 2013 г.), 39\% жителей еще не являются его пользователями. Кроме того, во многих случаях россияне пользуются интернетом не только как источником информации. Посещают сетевые ресурсы для общения 34\%, для развлечения 30\% пользователей, смотрят и скачивают фильмы и музыку - 27 и 25\% соответственно (табл. 3). Только 27\% пользуются интернетом, чтобы следить за последними новостями, а $18 \%$ посетителей, чтобы разобраться в происходящих событиях в России и за рубежом.

${ }^{1}$ Опросы проводились два раза в год в Вологде и Череповце, а также в восьми районах области (Бабаевском, Великоустюгском, Вожегодском, Грязовецком, Кирилловском, Никольском, Тарногском, Шекснинском). Метод опроса - анкетирование по месту жительства респондентов. Объем выборочной совокупности - 1500 человек в возрасте 18 лет и старше. Выборка целенаправленная, квотная. Репрезентативность выборки обеспечивается соблюдением пропорций между городским и сельским населением, между жителями населенных пунктов различных типов (сельские населенные пункты, малые и средние города), половозрастной структуры взрослого населения области. Ошибка выборки не превышает $3 \%$. 
Результаты опроса общественного мнения, проведенного ВЦИОМ в 2012 г., также подтверждают, что $39 \%$ россиян не пользуются интернетом для получения информации (табл. 4). Приоритетное значение по-прежнему имеет центральное телевидение (78\% используют его «часто»), региональное и местное телевещание $(52 \%)$.

Таблица 3

Пользуетесь ли Вы Интернетом, и если да, то для каких целей?, \% [5]

\begin{tabular}{|c|c|c|}
\hline \multirow[t]{2}{*}{ Варианты ответов } & \multicolumn{2}{|c|}{$\begin{array}{l}\text { Время проведения } \\
\text { опроса }\end{array}$} \\
\hline & 2012 г. & 2013 г. \\
\hline для того чтобы найти нужную мне информацию & 39 & 44 \\
\hline не пользуюсь интернетом & 46 & 39 \\
\hline для общения & 29 & 34 \\
\hline для развлечения & 22 & 30 \\
\hline для того чтобы войти в социальную сеть /сети* & - & 30 \\
\hline для того чтобы найти /посмотреть какие-либо фильмы & 22 & 27 \\
\hline для того чтобы следить за последними новостями & 29 & 27 \\
\hline для того чтобы найти / послушать какую-либо музыку & 20 & 25 \\
\hline $\begin{array}{l}\text { для того чтобы разобраться, что происходит в стране и за } \\
\text { рубежом }\end{array}$ & 15 & 18 \\
\hline для того чтобы найти / купить какие-либо товары или услуги & 12 & 17 \\
\hline для того чтобы найти / прочитать какие-либо книги & 12 & 14 \\
\hline Другое & 1 & 1 \\
\hline \multicolumn{3}{|c|}{$\begin{array}{l}\text { * В } 2012 \text { году не задавался. } \\
\text { Опрос проводился «Левада-центром» 23-26 августа } 2013 \text { г. по репрезентативной } \\
\text { выборке городского и сельского населения среди } 1601 \text { человек возрасте от } 18 \text { лет и } \\
\text { старше в } 130 \text { населенных пунктах } 45 \text { регионов России. Погрешность не более } 3,4 \%\end{array}$} \\
\hline
\end{tabular}

Печатные СМИ разного уровня сохраняю между собой паритет, их чаще или реже используют для получения информации $68-70 \%$ россиян. В последние годы они потеряли свою прежнюю информационно-аналитическую роль, хотя ранее выигрывали за счёт информативности и обстоятельности рассуждения. Одной из тенденций является максимальное упрощение контента современных источников информации, связанное с законом больших аудиторий: «чем проще содержание, тем шире аудитория». В итоге на место серьёзной аналитики, непонятной массовому потребителю, приходят поверхностные и банальные интерпретации и мнения [18, c. 139]. Кроме того, чтобы сохранить влияние, традиционные СМИ сегодня вкладывают средства в развитие собственных ресурсов и наращивают своё присутствие в интернете [8, с. 51]. Однако, как отмечает Е.Ю. Сергеев, печатные масс-медиа сохраняют прочные позиции, поскольку объединение различных видов информации в едином телевизионном или компьютерном варианте не отменяет текста [15, с. 121].

Радиовещание постепенно утрачивает свою роль массового источника новостей и иной информации: никогда не используют центральное радио $44 \%$ жителей страны, региональное и местное радио - $51 \%$ (табл. 4).

Таблица 4

Как часто Вы получаете информацию из следующих СМИ?, \% [3]

\begin{tabular}{|l|c|c|c|c|}
\hline \multirow{2}{*}{ Вид СМИ } & \multicolumn{4}{|c|}{ Вариант ответа } \\
\cline { 2 - 4 } & Часто & Редко & Никогда & Затрудняюсь \\
\hline
\end{tabular}




\begin{tabular}{|l|c|c|c|c|}
\hline & & & & ответить \\
\hline Центральное телевидение & 78 & 20 & 1 & 1 \\
\hline Региональное, местное телевидение & 52 & 36 & 10 & 2 \\
\hline Центральная пресса & 27 & 43 & 28 & 2 \\
\hline Региональная, местная пресса & 26 & 42 & 30 & 2 \\
\hline Интернет & 39 & 20 & 39 & 2 \\
\hline Центральное радио & 23 & 30 & 44 & 3 \\
\hline Региональное, местное радио & 17 & 19 & 51 & 4 \\
\hline Зарубежные СМИ & 6 & 20 & 69 & 5 \\
\hline
\end{tabular}

Опрос проведен ВЦИОМ 21-22 апреля 2012 г. среди 1600 респондентов из 138 населенных пунктов 46 регионов России. Статистическая погрешность 3-4\%.

Данные опроса общественного мнения населения области (декабрь 2013 г.) показывают, что 39\% жителей пользуются интернетом в целях общения, 33\% следят за новостями, 23\% - для расширения кругозора и получения необходимой информации (табл. 5). Выше среднеобластных показателей удельный вес череповчан, которые, судя по результатам опроса, более пристально следят за событиями в мире и в стране (47\% против 33 по области), а также пользуются сетевыми ресурсами для расширения кругозора (29\% против 23 в среднем по области).

Таблица 5

Для каких целей Вы чаще всего пользуетесь Интернетом?, \% *

\begin{tabular}{|c|c|c|c|c|}
\hline Варианты ответов & Вологда & Череповец & районы & область \\
\hline $\begin{array}{l}\text { Для того чтобы следить за новостями, } \\
\text { событиями в мире, в стране }\end{array}$ & 40,1 & 46,7 & 21,8 & 33,0 \\
\hline Для работы / учёбы & 36,9 & 33,0 & 21,3 & 28,3 \\
\hline Для того чтобы слушать / скачивать музыку & 12,0 & 12,7 & 4,8 & 8,7 \\
\hline Для того чтобы смотреть / скачивать фильмы & 17,5 & 14,2 & 5,2 & 10,7 \\
\hline Для того чтобы читать / скачивать книги & 7,6 & 5,8 & 2,2 & 4,5 \\
\hline Для того чтобы играть & 8,9 & 10,7 & 9,4 & 9,6 \\
\hline $\begin{array}{l}\text { Для общения с другими пользователями в } \\
\text { чатах, на форумах }\end{array}$ & 38,7 & 39,3 & 38,0 & 38,5 \\
\hline Для совершения покупок онлайн & 9,2 & 4,8 & 4,7 & 5,9 \\
\hline $\begin{array}{l}\text { Для расширения кругозора, получения } \\
\text { необходимой информации }\end{array}$ & 20,9 & 29,4 & 19,8 & 22,6 \\
\hline Другое & 0,3 & 1,0 & 0,8 & 0,7 \\
\hline
\end{tabular}

С развитием интернета изменилась модель потребления информации пользователями. Из-за переизбытка информации её потребители предъявляют повышенные требования к СМИ: им нужны не просто новости, но необходимы новости проверенные и персонализированные. Пользователи останавливаются на определённых брендах, доказавших свою эффективность, доверяют им.

Однако массированный информационный поток, обрушившийся на российскую общественность, не исключает информационного дефицита. В частности, масс-медиа слабо освещают деятельность общественных институтов, их успехи, достижения и трудности. Это не позволяет населению адекватно оценить их значение, основные формы и функции. Таким образом, власти, контролирующие большинство СМИ, во 
многом ответственны за невозможность общества осознать свою значимость и самоорганизоваться для решения жизненно-важных проблем. В ряде случаев можно говорить о сознательном завуалировании, размытии образа гражданского общества в целях не допустить создания влиятельной политической и социальной силы [9, с. 230]. Не случайно, по данным ИСЭРТ РАН, так низок уровень доверия к институтам гражданского общества, во многом обусловленный дефицитом информации об их деятельности. В 2012 г. доверяли СМИ 30\% жителей области, общественным организациям - 27\%, профсоюзам - 26\%, политическим партиям и движениям $-21 \%$ [7, c. 100-115].

Различается уровень доверия россиян к различным видам СМИ. Лучшими показателями по доверию граждан, по данным опроса ВЦИОМ от апреля 2012 г., обладает телевидение (табл. 6). Доверяет и скорее доверяет центральному, региональному и местному телевидению 78\% населения, печатным СМИ - 68-70\%, интернету $-64 \%$.

Доверяете ли Вы следующим СМИ?, \% [3]

Таблица 6

\begin{tabular}{|l|c|c|c|c|}
\hline \multirow{2}{*}{\multicolumn{1}{c|}{ Вид СМИ }} & \multicolumn{4}{c|}{ Вариант ответа } \\
\cline { 2 - 5 } & Да & $\begin{array}{c}\text { Скорее } \\
\text { доверяю }\end{array}$ & $\begin{array}{c}\text { Скорее } \\
\text { не доверяю }\end{array}$ & Нет \\
\hline Центральное телевидение & 36 & 42 & 16 & 3 \\
\hline Региональное, местное телевидение & 30 & 48 & 15 & 3 \\
\hline Центральная пресса & 23 & 47 & 21 & 4 \\
\hline Региональная, местная пресса & 21 & 47 & 21 & 5 \\
\hline Интернет & 23 & 41 & 22 & 7 \\
\hline Центральное радио & 26 & 46 & 16 & 3 \\
\hline Региональное, местное радио & 24 & 42 & 19 & 4 \\
\hline Зарубежные СМИ & 13 & 30 & 30 & 7 \\
\hline $\begin{array}{l}\text { Опрос проведен ВЦИОМ 21-22 апреля 2012 г. среди 1600 респондентов из } 138 \\
\text { населенных пунктов 46 регионов России. Статистическая погрешность 3-4\%. }\end{array}$ \\
\hline
\end{tabular}

Согласно проведенному РИАН исследованию, российские пользователи Интернета проявляют все больший интерес к новостным ресурсам сети. Вместе с тем телевидение в качестве источника информации теряет свои позиции.

В изучении тенденций развития новостной отрасли были задействованы медиаэксперты, а также руководители наиболее известных в России СМИ. По итогам проведенного анализа, очевидно, что интернет как источник информации завоевывает все большее доверие и интерес пользователей как в России, так и за рубежом. В течение 2012 г. аудитория в категории News/Information по всему миру выросла на 5\%. По данным TNS WebIndex, за аналогичный период $61 \%$ российских пользователей интернета (21,9 млн. чел.) являются посетителями новостных ресурсов. По сравнению с 2011 г. этот показатель вырос на 13,2\%, в то время как общий прирост интернетаудитории составил 13\%. Данные указывают на заметный рост использования сети интернет и её новостных ресурсов. Помимо этого наблюдается повышение доверия к данному источнику информации. ФОМ отмечает, что в 2010 г. лишь 4\% россиян выделяли новостные сайты как самый надежный источник информации, а в 2012 году указанный показатель составил уже $11 \%$. По отношению к телевидению наблюдается обратная тенденция. По информации ФОМ, в 2010 г. 71\% респондентов выделял телевидение как самый надежный источник новостей, а в 2012 году данный показатель снизился до 57\%. [6]. 
Динамика уровня доверия к СМИ отражена в табл. 7. Как видно из представленной таблицы, за последние годы средние показатели по Вологодской области не подверглись существенным изменениям. При этом доля граждан доверяющих масс-медиа и не доверяющих им практически одинакова. За последние три года доверяли СМИ 29-30\% жителей области, а не доверяли 28-31\%.

Таблица 7

Доверяете ли Вы средствам массовой информации?, \%

\begin{tabular}{|c|c|c|}
\hline $\begin{array}{c}\text { Годы } \\
\text { (средний показатель) }\end{array}$ & $\begin{array}{c}\text { Полностью и } \\
\text { в основном доверяю }\end{array}$ & $\begin{array}{c}\text { Полностью и } \\
\text { в основном не доверяю }\end{array}$ \\
\hline 2008 & 35,2 & 29,5 \\
\hline 2009 & 28,7 & 27,1 \\
\hline 2010 & 29,2 & 33,3 \\
\hline 2011 & 28,7 & 31,1 \\
\hline 2012 & 29,5 & 27,6 \\
\hline 2013 & 30,2 & 28,2 \\
\hline
\end{tabular}

Данные последнего мониторинга ИСЭРТ РАН (декабрь 2013 г.) показали, что среди СМИ телевидение сохраняет наиболее высокий уровень доверия - 53\% в среднем по области (в Вологде - 58\%, в Череповце - 66\%) (табл. 8). Газетам доверяют 40\% населения области (среди череповчан - 53\%), радио - 33\% (52\% жителей Череповца), Интернету - 32\% (52\% жителей Череповца). Ниже среднеобластного уровень доверия к СМИ наиболее характерен для жителей районов Вологодской области.

Представляет интерес и вопрос о роли средств массовой информации в жизни страны. По данным ИСЭРТ РАН, более половины населения области положительно оценивает роль СМИ в жизни общества (табл. 9). Однако удельный вес позитивно настроенных жителей постепенно снижается, а давших им отрицательную оценку возрастает.

Экономический кризис 2008-2009 гг. сыграл негативную роль для СМИ. Вопервых, в этот период в них недостаточно полно и объективно отражалось положение дел в экономике, что являлось насущной потребностью значительной части населения страны. Во-вторых, падение доходов от рекламы и оптимизация расходов снизили качество контента - основной ценности для общества.

Таблица 8

Уровень доверия жителей Вологодской области к различным СМИ, \% *

\begin{tabular}{|c|c|c|c|c|c|}
\hline $\begin{array}{c}\text { Вид } \\
\text { СМИ }\end{array}$ & Варианты ответов & 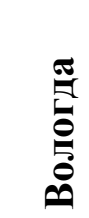 & 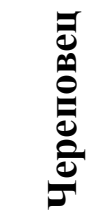 & & 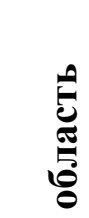 \\
\hline \multirow{3}{*}{ Радио } & Полностью и в основном доверяю & 37,2 & 51,8 & 19,6 & 32,5 \\
\hline & Полностью и в основном не доверяю & 9,2 & 9,1 & 3,5 & 6,4 \\
\hline & Затрудняюсь ответить & 11,0 & 16,2 & 19,1 & 16,3 \\
\hline \multirow{3}{*}{$\begin{array}{l}\text { Телеви- } \\
\text { дение }\end{array}$} & Полностью и в основном доверяю & 57,9 & 66,0 & 43,6 & 53,1 \\
\hline & Полностью и в основном не доверяю & 14,1 & 12,4 & 4,8 & 9,2 \\
\hline & Затрудняюсь ответить & 4,7 & 5,8 & 10,6 & 7,9 \\
\hline
\end{tabular}


ISPC «Scientific technologies of the future», 28.02.2014

\begin{tabular}{|c|c|c|c|c|c|}
\hline \multirow{3}{*}{ Газеты } & Полностью и в основном доверяю & 38,5 & 52,5 & 34,4 & 40,2 \\
\hline & Полностью и в основном не доверяю & 12,6 & 15,2 & 5,5 & 9,9 \\
\hline & Затрудняюсь ответить & 7,6 & 11,7 & 14,0 & 11,7 \\
\hline \multirow{3}{*}{ Журналы } & Полностью и в основном доверяю & 25,4 & 33,0 & 15,2 & 22,5 \\
\hline & Полностью и в основном не доверяю & 18,3 & 18,8 & 7,5 & 13,2 \\
\hline & Затрудняюсь ответить & 10,2 & 19,0 & 19,8 & 17,1 \\
\hline \multirow{3}{*}{ Интернет } & Полностью и в основном доверяю & 33,2 & 52,0 & 20,3 & 31,9 \\
\hline & Полностью и в основном не доверяю & 12,0 & 10,9 & 2,9 & 7,3 \\
\hline & Затрудняюсь ответить & 11,8 & 11,9 & 22,1 & 16,8 \\
\hline Никаким & & 2,9 & 1,8 & 2,3 & 2,3 \\
\hline
\end{tabular}

Телевидение сохраняет свои позиции и остается основным источником информации о политической и экономической жизни для $84 \%$ населения, а также сведений культурно-развлекательного характера для 79\%. Половина населения области узнает новости культуры и спорта из печатных изданий (46\%). Радио - менее востребованный информационный ресурс, чем Интернет (23\% против 37$)$.

Таблица 9

Как Вы считаете, какую роль в жизни страны играют газеты, радио и телевидение?, \%

\begin{tabular}{|c|c|c|}
\hline Годы & $\begin{array}{c}\text { Положительную и } \\
\text { скорее положительную }\end{array}$ & $\begin{array}{c}\text { Отрицательную и } \\
\text { скорее отрицательную }\end{array}$ \\
\hline 2008 & 63,9 & 15,5 \\
\hline 2009 & 67,1 & 13,7 \\
\hline 2010 & 62,9 & 16,9 \\
\hline 2011 & 57,1 & 15,3 \\
\hline 2012 & 58,9 & 14,9 \\
\hline 2013 & 52,5 & 21,1 \\
\hline \multicolumn{2}{|l}{} \\
\hline \multicolumn{2}{|l}{} \\
\hline
\end{tabular}

В последние годы изменился характер потребления информации. Развитие электронных СМИ и сетевых коммуникаций, повсеместный переход на цифровые стандарты формируют своеобразное «цифровое» массовое сознание. Человек не стремится что-либо познать, осмыслить, проанализировать. Потребностью для него выступает простой сбор различной информации, при этом в абсолютно сжатом, концентрированном виде. Как указывает М.В. Синдинская, жители мегаполиса хотят воспринимать информацию на ходу, во время перемещения. Всё больше людей не имеют (и не хотят!) читать длинные тексты, они ориентируются больше на фотографии и картинки: идёт переориентация читателя на онлайн [16, с. 49].

Учитывая обилие информационных потоков, необходимая информация либо забывается, либо остаётся невостребованной. Отсутствие необходимой фильтрации поступающих сведений, их логического и критического осмысления препятствуют формированию собственных позиций и взглядов человека. Данное обстоятельство негативно сказывается на развитии институтов гражданского общества, в том числе оппозиции [9, с. 226-227.].

В исследованиях также отмечается отсутствие у населения потребности в независимой прессе и нежелание отстаивать самостоятельности СМИ. Большинство 
журналистов сами скептически относятся к идее независимой прессы [20, с. 69]. Относительно самостоятельные масс-медиа не обладают достаточными техническими либо кадровыми возможностями для оказания качественных информационных услуг и обеспечения доступа к ним широкой общественности. В итоге мы получаем «низкопробные» программы и статьи, которые не вызывают интереса у потребителя, а порой даже раздражают его. По данным ИСЭРТ РАН, до половины жителей области демонстрируют желание ограничить свободу СМИ и ввести цензуру (табл. 10). По мнению С.Ю. Лисовой, такие показатели свидетельствуют об инфантилизме психологии российского социума, когда индивиды не могут решить вопрос о том, что им смотреть, слушать или читать, полагаясь на мнение государственной инстанции [9, c. 230].

Таблица 10

Как Вы считаете, нужна ли цензура в средствах массовой информации?, \%*

\begin{tabular}{|c|c|c|c|c|c|c|}
\hline Варианты ответов & 2008 & 2009 & 2010 & 2011 & 2012 & 2013 \\
\hline Обязательно и скорее нужна & 64,7 & 59,3 & 55,9 & 49,7 & 45,3 & 48,7 \\
\hline Совсем и скорее не нужна & 18,3 & 19,6 & 27,7 & 25,1 & 32,2 & 22,6 \\
\hline Затрудняюсь ответить & 17,0 & 21,1 & 16,4 & 25,2 & 22,5 & 28,7 \\
\hline
\end{tabular}

Масс-медиа находятся в условиях жесткой конкуренции и не могут развиваться, не по законам экономики. Продукт СМИ должен найти своего потребителя, а для этого он должен быть конкурентоспособным. Именно тематика отличает одно издание от другого и определяет его аудиторию. Если ежедневное издание может претендовать на оперативность в подаче новостей, то еженедельные газеты не успевают за электронными СМИ. Важную роль для печатных изданий играют условия их распространения [1, с. 112].

Большинство СМИ оказались не готовы выживать в условиях рыночной конкуренции, столкнувшись с необходимостью поиска спонсоров и рекламодателей. Примечательно, что в современной России роль инвестора для них всё чаще берут на себя государство или крупные корпорации. Поэтому в современной ситуации ценностные программы и образцы поведения задают государственные и коммерческие СМИ, исходящие из политических и экономических стратегий хозяина [19, с. 131]. По мнению Н.И. Гайтюкевич, СМИ порой играют весьма опасную роль, когда подменяют свою изначальную функцию (объективное информирование населения) на выполнение задач по формированию определенных взглядов, мнений, представлений [4, с. 276].

Результаты исследования российского медийного пространства показывают, что быстрыми темпами развиваются в основном электронные СМИ благодаря оперативности размещения информации и их относительной независимости. Традиционные масс-медиа продолжают соперничество, занимая свой сегмент рынка информации, и параллельно создавая свои сетевые ресурсы. Негативной тенденцией в данной сфере является снижение уровня доверия россиян к средствам массовой информации. Государство, заинтересованное в укреплении институтов гражданского общества, должно создать условия для существования независимых СМИ и конкурентного рынка информации. Масс-медиа, в свою очередь, необходимо повысить уровень и качество своего контента, стимулировать рост профессионального уровня журналистов. 


\section{Литература}

1. Багдадян Я.В. Условия обеспечения конкурентоспособности печатных СМИ // Вестник Адыгейского государственного университета. Серия 2: Филология и искусствоведение. 2008. № 10. С. 110-113.

2. Бузин В.Н. Возможен ли закат телевидения? Социологический прогноз // Социологические исследования. 2012. № 10. С. 93-98.

3. «Вся правда - в телевизоре?»// ВЦИОМ. Пресс-выпуск № 2081. URL: http://wciom.ru/index.php?id=459\&uid=112941

4. Гайтюкевич Н.И. Роль и место СМИ в системе современных средств массовых коммуникаций // Знание. Понимание. Умение. 2011. № 2. С. 274-277.

5. Интернет и СMИ. Левада-центр. Аналитический центр Юрия Левады. URL: http://www.levada.ru/19-09-2013/internet-i-smi

6. Исследование РИА Новости выявило повышение доверия к интернет-СМИ и снижение доверия к телевидению. URL: http://www.vivanti.ru/ru/news/details/48

7. Кожина Т.П. Институциональное доверие: региональный аспект // Проблемы развития территорий. 2013. № 3. С. 100-115.

8. Кондрашина М.Н. Российские СМИ в условиях диверсификации публичной сферы // Вестник Томского государственного университета. Философия. Социология. Политология. 2010. № 3 (11). С. 40-54.

9. Лисова С.Ю. Средства массовой коммуникации в процессе становления гражданского общества // Научные ведомости Белгородского государственного университета. Серия: История. Политология. Экономика. Информатика. 2009. № 11. C. 223-233.

10. Масс-медиа - главный источник информации для россиян. URL: http://wciom.ru/index.php?id=459\&uid=111297

11. Овчинская Е.В. Трансформация практик телепотребления в России // Социологические исследования. 2011. № 5. С. 129-132.

12. Ползучая медиа-революция // Левада-центр. Аналитический центр Юрия Левады. URL: http://www.levada.ru/09-07-2013/polzuchaya-media-revolyutsiya

13. Российские СМИ сегодня и их аудитория. URL: http://wciom.ru/index.php?id=270\&uid=112076

14. Самый надёжный источник. // Левада-центр. Аналитический центр Юрия Левады. URL: http://www.levada.ru/09-07-2013/samyi-nadezhnyi-istochnik

15. Сергеев Е.Ю. СМИ в условиях глобализации // Общество. Среда. Развитие (Terra Humana). 2009. № 1. С. 117-126.

16. Синдинская М.В. Печатные СМИ. Расширение возможностей // Вестник Московского государственного гуманитарного университета им. М.А. Шолохова. Филологические науки. 2010. № 4. С. 45-49.

17. Тен Ю. Ящик сыграл в ящик // Эксперт. Казахстан. 5 марта 2013 г. URL: http://expertonline.kz/a10381/

18. Чубик А.П. Реальность и СМИ // Известия Томского политехнического университета. 2012. № 6. С. 136-139.

19. Щербинин А.И., Гоманович Н.В., Ершова И.А. СМИ как фактор российского политического процесса на рубеже XX-XXI вв. (аксиологический аспект) // Вестник Томского государственного университета. 2007. № 294. С. 129-131.

20. Ющенко М.А. Средства массовой коммуникации как механизм формирования властью общественного сознания граждан // Вестник Томского государственного университета. 2007. № 305. С. 67-70. 